\title{
Parecer CNE/CEB nำ1, de 29 de Janeiro de 1999
}

MANTENEDORA/INTERESSADO: Conselho Nacional de Educação/Câmara de Educação Básica - Brasília - DF

ASSUNTO: Diretrizes Curriculares Nacionais para a formação de professores na modalidade normal em nível médio.

RELATOR(A) CONSELHEIRO(A): Edla de Araújo Lira Soares

PROCESSO №: 23001.000037/99-18

PARECER CEB №: $1 / 99$ CÂMARA OU COMISSÂO:CEB

APROVADO EM: 29/1/99

\section{Relatório}

Este Parecer dirige-se, especialmente, aos professores que, inspirados nos ideais de solidariedade, liberdade e justiça social, pretendem exercer a docência na Educação Infantil e nas quatro primeiras séries do Ensino Fundamental, tendo como perspectiva a educação escolar, direito de todos e dimensão inalienável da cidadania plena, na sociedade contemporânea.

É por essa convicção que os estudos e as reflexões sobre a formação de docentes, encontram no pensamento do Professor Paulo Freire pontos que são fundamentais para a organização e o desenvolvimento das propostas pedagógicas das escolas.

(...) O espaço de que disponho não me permite ir além de algumas rápidas considerações em torno de um ou dois pontos que me parecem fundamentais em nossa prática. Pontos, de resto, ligados entre si, um implicando no outro.

O primeiro deles é o da necessidade que temos, educadoras e educadores, de viver, na prática, o reconhecimento óbvio de que nem um de nós está só no mundo. Cada um de nós é um ser no mundo, com o mundo e com os outros. Viver ou encarnar esta constatação evidente, enquanto educadora ou 
educador, significa reconhecer nos outros - os educandos no nosso caso - o direito de dizer a sua palavra. Direito deles de falar que corresponde ao nosso dever de escutá-los.

Mas, como escutar implica em falar também, o dever que temos de escutálos significa o direito que igualmente temos de falar-lhes. Escutá-los, no fundo, é falar com eles, enquanto simplesmente falar a eles seria uma forma de não ouvi-los. Dizer-Ihes sempre a nossa palavra, sem jamais nos oferecermos às palavras deles, arrogantemente convencidos de que estamos aqui para salvá-los, é um boa maneira que temos de afirmar o nosso elitismo, sempre autoritário.

Esta não pode ser, porém, a maneira de atuar de uma educadora ou de um educador cuja opção é libertadora. Quem assim trabalha, consciente ou inconscientemente, ajuda a preservação das estruturas dominadoras.

O outro ponto, ligado a este, e a que eu gostaria de me referir é o da necessidade que temos os educadores e educadoras de "assumir" a ingenuidade dos educandos para poder, com eles, superá-la. Estando num lado da rua ninguém estará, em seguida, no outro, a não ser atravessando a rua. Se estou do lado de cá, não posso chegar ao lado de lá, partindo de lá, mas de cá. (...)

Sejamos coerentes. Já é tempo. Fraternalmente,

$$
\text { Paulo Freire }
$$

São Paulo, abril de 1982. (Gadotti 1996)

\section{Introdução}

A Lei 9131, de 20 de dezembro de 1996, que instituiu o atual Conselho Nacional de Educação, consignou, entre as competências da Câmara de Educação Básica - CEB, deliberar sobre as Diretrizes Curriculares Nacionais - DCN. Nessa atribuição, a CEB identifica uma efetiva possibilidade de suas ações contribuírem para consolidar o processo que busca um padrão de qualidade para a educação básica no país. No encaminhamento dessa missão, a Câmara iniciou estudos e solicitou, através de audiências públicas, a valiosa colaboração de instituições e entidades com tradição no planejamento, na execução e na avaliação de políticas educacionais, bem como no desenvolvimento de pesquisas no campo educacional.

Até o momento, o processo de estudos e consultas resultou na elaboração dos Pareceres, ${ }^{\text {os }}$ 22/98, 04/98 e 15/98 que tratam das diretrizes norteadoras da educação infantil e do ensino fundamental e médio. 
Ao serem aprovadas e homologadas, essas diretrizes adquiriram, segundo a legislação vigente, a condição de mandatórias. Essa condição, entretanto, não interrompeu as interlocuções que se instalaram, desde as origens da sua elaboração; prosseguem as discussões e negociações, tendo em vista traduzir as citadas diretrizes em efetivas possibilidades de articulação das diversas propostas pedagógicas das escolas.

Sabe-se, neste caso, que o exercício das responsabilidades dos entes federativos com a universalização da educação de qualidade, nos termos do que estabelecem as DCN, pressupõem, simultaneamente, um efetivo regime de colaboração e o controle público das políticas educacionais em curso no país.

Com essa perspectiva, o presente parecer, ao propor diretrizes curriculares nacionais para a formação de professores na modalidade Normal, em nível médio, retoma os princípios das DCN até então aprovadas e observa as contribuições contidas nos referenciais para formação de professores sugeridos pela Secretaria de Ensino Fundamental do MEC, as orientações da proposta de Curso Normal Superior a distância, formuladas pela Fundação Darcy Ribeiro e as discussões que subsidiaram o programa de formação de professores em exercício, coordenado pela Secretaria do Ensino a Distância do MEC. Também, como não poderia deixar de ser, este parecer foi enriquecido pelo instigante e atual debate sobre a formação do educador. Cabe ainda destacar as relevantes contribuições oferecidas pelos Conselheiros da CEB, durante o processo de construção dessa proposta, em especial as dos Conselheiros Regina Alcântara de Assis e João Antônio Cabral de Monlevade e da ex-Conselheira Hermengarda Ludke.

\section{Profissionalização do educador: Identidade e formação}

O reconhecimento da centralidade da educação escolar no contexto das transformações que perpassam todas as dimensões da nação brasileira tem subsidiado um fecundo debate sobre os diversos fatores que influenciam na democratização das políticas de Estado para o setor. O Brasil, em que pese ter assegurado o acesso de $95 \%$ das crianças e jovens, dos 7 aos 14 anos, ao ensino obrigatório, ainda convive com milhões de analfabetos, jovens e adultos. Além disso, suas escolas registram significativos índices de evasão e repetência.

Assim, enquanto a humanidade já produziu tecnologias de ponta que aproximam o local, o nacional e o internacional e se lança para o cosmo, o país ainda não conseguiu cumprir a meta de universalização do ensino fun- 
damental de qualidade, reduzindo com isso as possibilidades de inserção de amplos segmentos da sociedade no espaço integrado e mundial do conhecimento e das informações. Acrescente-se, ainda, que a agenda de mudanças para o setor educacional nem sempre contempla compromissos com a modificação da feição excludente dos sistemas de ensino. É o caso, por exemplo, das reformas que se processam no bojo dos programas de ajuste estrutural. Esses, por sua vez, implicam enormes custos sociais e dão especial destaque ao capital financeiro, repondo com mais força a necessidade de se preservar direitos sociais já conquistados.

Por outro lado, com o avanço do processo democrático, as demandas da população no campo educacional têm um objetivo claro. Traduzem anseios por melhoria da qualidade de vida e exercício da cidadania plena, no âmbito da criação ininterrupta de novos direitos e subversão contínua do estabelecido (Lefort 1987). Nesse aspecto, verifica-se que o reconhecimento da importância do papel do professor nas mudanças educacionais pretendidas tem estimulado a formulação de proposições inovadoras para os sistemas de formação de docentes, com visibilidade na legislação educacional e nos meios de comunicação.

Em sintonia com essas expectativas, a Lei 9394/96 toma a escola como foco de suas preocupações (art. 12), conferindo, quando comparada às demais, um especial destaque às incumbências dos professores (art.13). Ao mesmo tempo que a União, os Estados, o Distrito Federal, os Municípios e os estabelecimentos de ensino (art. 9, 10, 11), os educadores são convocados, em articulação com as famílias e a comunidade, a assumirem um compromisso ético com os alunos e as suas diferentes histórias de vida, no contexto do atendimento escolar sob a ótica do direito. A redescoberta do valor da escola, do professor e da participação da sociedade, nos termos da citada lei, retira o processo de escolarização do isolamento social e da responsabilidade individual, insistindo na dimensão coletiva do trabalho pedagógico e no caráter democrático de seus propósitos, de sua execução e avaliação.

Neste sentido, o processo de escolarização vai adquirindo um novo significado social e cultural, claramente expresso nos princípios e fins da educação nacional, que estão inscritos nos termos da citada lei, manifestando a vontade da nação.

Trata-se de estimular formas de pensamentos e ações que conectem as instituições educacionais com as organizações da sociedade civil, possibilitando interrogar sobre as relações do cotidiano escolar, as escolhas de conteúdos, programas e atividades à luz do jogo de interesses e respectivos valores que moldam a educação e a sociedade. 
No art. $1^{\circ}$ do Título I da Lei de Diretrizes e Bases da Educação Nacional (LDBEN) é explicitada a concepção de educação que orienta os dispositivos do conjunto do texto. De caráter abrangente, contempla os processos formativos que se desenvolvem na vida familiar, na convivência humana, no trabalho, nas instituições de ensino e pesquisa, nos movimentos sociais e organizações da sociedade civil e nas manifestações culturais. Por sua vez, o segundo parágrafo do mesmo artigo consagra a dimensão socialmente contextualizada da educação escolar, estabelecendo que deverá vincular-se ao mundo do trabalho e da prática social. Há, portanto, o propósito social e a referência a uma práxis. Pressupõe, simultaneamente, saber, decidir e atuar. Desvenda, a partir de uma visão global e integrada do processo educacional, a falácia da oposição entre saber e fazer, conhecer e aplicar. Fica definido, a partir desse Título, que a docência supõe a competência para remeter o conhecimento à prática e ao conjunto das situações que enfrenta o profissional da educação no cotidiano escolar.

No Título II, o propósito social que referenda a educação, a partir do seu vínculo com o trabalho e a prática social, é ampliado. No caso, além de estabelecer as responsabilidades da Família e do Estado com a educação, declara sua inspiração nos princípios de liberdade e nos ideais de solidariedade humana. Com isto, possibilita a busca de espelhos e imagens para o desenvolvimento de um projeto de educação escolar que inclua a diversidade e elimine a discriminação em todos os níveis de ensino.

Por certo, essa perspectiva aponta para ambientes de aprendizagens colaborativas e interativas. Quer se considere os integrantes de uma mesma escola, quer se eleja atores de projetos pedagógicos de diferentes instituições, sistemas de ensino e lugares. Abre-se, assim, um horizonte interinstitucional de colaboração que é decisivo para a formação dos professores.

Neste particular, delineia-se um significado social para o uso de novas tecnologias e múltiplas linguagens, tendo em vista um trabalho conjunto e solidário, com benefícios para comunidades locais, regionais, nacionais e intercontinentais. Numa cultura que cresce em redes de conhecimento e em relações de escala global, numa mídia em que verdades e mentiras se encontram justapostas, o discernimento de conhecimentos e valores não prescinde do mestre, um mestre distinto, afeito também a uma nova cultura, a fim de desfazer equívocos e ressaltar informações pertinentes.

$\mathrm{Na}$ verdade, a LDBEN dá especial destaque ao papel do professor, tornando público (art.13,III), que a sua função social é zelar, no contexto do dever do Estado pela educação escolar, pelo exercício do direito de aprender de cada aluno. Ao fazê-lo, a lei interpela o profissional da edu- 
cação, enquanto um intelectual que tem poder, face às várias possibilidades de escolha, de firmar compromissos com os interesses mais gerais do conjunto do país. Assim, como a CEB já manifestou no Parecer 04/98, a nação brasileira, através de suas instituições, e no âmbito de seus entes federativos, vem assumindo, vigorosamente, responsabilidades crescentes para que a Educação Básica, demanda primeira das sociedades democráticas, seja prioridade nacional como garantia inalienável do exercício da cidadania plena.

De fato, no estabelecimento desses compromissos encontra-se o valor intrínseco da atividade docente e a principal contribuição para tecer a sua legitimidade, aproximando a dignidade da profissão dos ideais da democracia.

Como se vê, a LDBEN está distante da visão instrumental que confinava os professores ao papel de meros executores. Estabelece, para os mesmos, entre outras atribuições, a sua participação na elaboração da proposta pedagógica (art. 13, I) e garante-Ihes tempo remunerado para preparação e avaliação do trabalho pedagógico (art. 67, V), no contexto de progressivos graus de autonomia da escola (art. 15). Nesse sentido, deve-se orientar a tarefa de repensar a formação docente, considerada em toda a sua complexidade. A referida tarefa tem influenciado o estado do debate a respeito do que se denominou "crise de identidade" dos professores. Nas últimas décadas, essa crise, provocada principalmente pela associação de fatores como baixos salários e multiplicação de jornadas de trabalho, reduziu a atividade docente à simples execução de atos fragmentados de "ensinar" ou "dar matéria". No caso, a formação desse profissional ficou reduzida à transmissão de conteúdos e procedimentos indispensáveis ao como fazer e o que fazer, estabelecidos nos limites da abordagem tecnocrática. Em decorrência, retirou-se do foco dos debates e estudos sobre a educação escolar as questões da natureza e do propósito da escolarização, da conexão entre escola e sociedade, da relação entre poder e ensino, da escola como organização social e da natureza do conhecimento escolar, entre tantas, esvaziando o domínio do educador sobre as suas condições de trabalho. Tal entendimento, no entanto, teve que enfrentar os protestos da sociedade democrática, que reconhece a relevância da formação desses profissionais que desempenham tão importantes papéis, notadamente no encaminhamento de políticas que estimulem a autonomia e valorizem a diversidade, num contexto de responsabilidade e liberdade.

Aqui, deve-se ressalvar a contribuição das análises que circunscrevem o reconhecimento social do magistério no campo das relações entre educação e cultura. Nunca é demais ressaltar a interação intrínseca entre 
ambas, dinâmica essa reconhecida no art. $1^{\circ}$ da LDBEN. O mundo da cultura é o mundo das possibilidades, de um equilíbrio que nunca se completa, um território de riscos e ousadias, onde se conflitam o que é tido como autorizado socialmente e a insuficiência do estatuto da tradição, para legitimar sua incorporação na proposta pedagógica das unidades educacionais. $\mathrm{Na}$ verdade, "não se confere igual valor a todos os elementos constitutivos da cultura."

Nesse cenário, o exercício da docência pressupõe uma arrojada tarefa, que não pode prescindir de estratégias interpretativas, na análise da pertinência social e dos desdobramentos das escolhas que são processadas. Assim, passa a ser configurada, no mínimo, uma dupla exigência, a partir da competência que tem o profissional da educação inspirada nos ideais da educação nacional.

Em primeiro lugar, contribuir, no exercício da atividade docente, para a produção de conhecimentos que favoreçam as leituras e as mudanças da realidade e, também, influenciar no processo de seleção do que representa "a experiência coletiva e a cultura viva de uma comunidade." Em função disso, o educador compartilha das decisões a respeito de quais saberes e materiais culturais deverão ser socializados, tendo em vista o exercício pleno da cidadania. Dessa forma, o professor assume sua condição de intelectual face à possibilidade de integrar-se no fecundo debate a respeito dos valores, das concepções e dos modos de convivência que deverão ser priorizados, através do currículo.

Em segundo lugar, e como desdobramento, entende-se que o direito de aprender, assegurado inclusive pela garantia das condições do direito de ensinar, pressupõe por parte do docente a reelaboração da ciência do sábio, da obra do escritor ou do artista (Forquin 1993) e, ainda, do pensamento teórico e da paixão geradora do sonho que se queira socializar, em situações específicas e nem sempre previsíveis. Direito de aprender, de futuros professores, que não respondem apenas a estímulos de seus formadores, mas exercitam a liberdade de crescer no conhecimento, aprofundar as críticas, resolver os problemas, cultivar os desafios da prática; mas, também, o dever de se preparar para a interlocução e para responder às mais avançadas e desafiantes perguntas que seus alunos vão Ihes propor. Alunos não idealizados, mas reais, antecipados na trama dos ambientes de aprendizagem que se constituem durante seu processo de formação.

Trata-se, no caso da educação escolar, de fazer face a uma situação singular e complexa, construindo respostas que trazem, sem a exacerbação do passado, as tonalidades do que já é conhecido e, sem o otimismo ingê- 
nuo, a radicalidade da utopia. Há sempre algo de inesperado que é próprio de uma sociedade instituinte, onde a vivência da subjetividade ultrapassa a abordagem exclusivamente científica de um projeto educacional. Assim, diversos e surpreendentes cantos podem propagar o eco da vida cidadã, abrindo-se também para a multiplicidade e desigualdade de contextos e desafios que fluem a partir das relações de gênero, etnia, trabalho, entre outras.

Neste processo, o educador compreende que os conhecimentos não podem ser simplesmente transferidos. Ensinar e aprender é sempre um ato único e criativo. Exige um esforço de construção através de uma atividade que é simultaneamente teórica e prática, individual e coletiva.

Aliás, refletir sobre a prática reorientando a ação docente constitui, segundo o art. 61 da LDBEN, um dos fundamentos da formação dos profissionais da educação. Nesse sentido, o ensino é uma atividade complexa que supõe uma reflexão sistemática sobre a prática, requerendo, para tanto, a constituição de conhecimentos, valores e competências estimuladoras de uma ação autônoma e, ao mesmo tempo, colaborativa em face da responsabilidade coletiva, com os procedimentos que deverão assegurar o direito dos alunos aprenderem.

Assim, no cumprimento do que estabelece o texto legal, o professor conduz sua própria formação, pensando a prática e tomando decisões sobre ambientes de aprendizagem que concretizam o projeto pedagógico elaborado pelo conjunto da escola. Ao se tornar sujeito da formação, torna-se também sujeito de sua própria valorização, no âmbito do que está posto no art. 67 da LDBEN.

Em vista disso, sua preparação é permanente e dá concretude, na utopia do saudoso Gonzaguinha, à beleza de ser um eterno aprendiz. Só assim, torna-se fator determinante da dinâmica educativa, aliado inconteste das reformas que se apresentam como alternativas de qualificação do processo educativo e, ainda, como declaram os teóricos da educação emancipatória, o intelectual que une, no contexto da sala de aula, a análise crítica com a possibilidade de mudança. Dessa forma, circunscreve o exercício da docência na inteligência maior a respeito dos problemas e das soluções encontradas coletivamente pela sociedade, assumindo de forma solidária sua condição de profissional.

Nesta direção, os legisladores consideram que a gestão democrática é uma das principais âncoras do processo de seleção e reelaboração que se instala na organização dos ambientes de aprendizagem escolar. Para tanto, retomam, no texto da LDBEN, através do que estabelecem os arts. 14 e 15, o que está disposto no parágrafo único do art. 
$1^{\circ}$ da Constituição Federal (CF), consagrando o princípio da gestão participativa e o controle público da qualidade da educação:

\section{Art. $1^{\circ}$}

Parágrafo único. Todo o poder emana do povo, que o exerce por meio de representantes eleitos ou diretamente, nos termos desta Constituição.

\section{Qurso Normal na trajetória da formação do professor}

A complexa relação entre a formação dos professores e a qualidade da Educação Infantil e do Ensino Fundamental (anos iniciais), vem sendo analisada, predominantemente, sob a ótica da 'universitarização' da formação inicial. É uma abordagem que, pelo seu caráter específico, tem estimulado o debate e o surgimento de inovações a respeito dos processos educacionais.

Do ponto de vista das organizações de educadores e das entidades que desenvolvem estudos e pesquisas sobre a formação docente, o tema vem sendo rigorosamente tratado no contexto de uma política global que contempla, simultaneamente, formação inicial e continuada, condições de trabalho, salário e carreira. Com isso, formulam severas críticas às análises que privilegiam aspectos particulares de uma problemática cuja solução pressupõe políticas de natureza global. Vale ressaltar, no entanto, que ao abordarem explicitamente a formação inicial pleiteiam seja a mesma desenvolvida em níveis mais elevados, tendo em vista a complexidade que consideram inerente à tarefa de ensinar.

No Brasil, em que pese o debate sobre a profissionalização do magistério apontar para esse patamar de escolarização mais elevado, a LDBEN, em seu art. 62, sem desconhecer a tendência mundial de formação docente em nível superior, admite a preparação do professor da educação infantil e dos anos iniciais do Ensino Fundamental, tanto em nível médio, quanto em nível superior:

Art. 62 - A formação de docentes para atuar na educação básica far-se-á em nível superior, em curso de licenciatura, de graduação plena em universidades e institutos superiores de educação admitida como formação mínima para o exercício do magistério na educação infantil e nas quatro primeiras séries do ensino fundamental, a oferecida em nível médio, na modalidade Normal. 
Tal flexibilidade é compatível com o esforço dos legisladores no sentido de contemplar a diversidade e a desigualdade de oportunidades que perpassam a realidade educacional no país. Sem criar impedimentos formais para a oferta dessa modalidade de atendimento educacional, de fato, a lei desafia os sistemas a repensá-la sob novas bases. A rigor, seu reconhecimento expressa um movimento em busca da recuperação da sua identidade, na medida em que é a única modalidade de educação profissional em nível médio que a lei reconhece e identifica. As políticas educacionais haverão de respeitar essa peculiaridade e envidar esforços para dar conseqüência à valorização do magistério em todas as suas dimensões.

Os indicadores dessas mudanças podem ser identificados no conjunto da LDBEN. Atente-se para os dispositivos a respeito das incumbências dos docentes (art. 13), as disposições gerais que orientam a educação básica e também as determinações para a educação infantil e o ensino fundamental (Seções II e III do Título V, Capítulo II). Considere-se, ainda, o estabelecido no art. 61 sobre os fundamentos da formação e, no art. 67 , sobre as condições pertinentes à profissionalização dos docentes.

Por sua vez, a Resolução no 03 do Conselho Nacional de Educação (CNE), que fixa Diretrizes para os Novos Planos de Carreira e de Remuneração do Magistério dos Estados, do Distrito Federal e dos Municípios, retoma o que está determinado no art. 62 da LDBEN, nos seguintes termos:

Art. $4^{\circ}$ - O exercício da docência na carreira do magistério exige, como qualificação mínima:

I- ensino médio completo, na modalidade Normal, para a docência na educação infantil e nas quatro primeiras séries do ensino fundamental.

Aproxima-se dessa linha o pronunciamento do Plano Nacional de Educação. Encaminhado ao Congresso pela União, reafirma a contribuição do curso de Magistério, propõe novas finalidades frente às demandas presentes na sociedade e alerta para os limites do seu atual formato.

Quanto à habilitação para o magistério em nível de $2^{\circ}$ grau, a Lei $\mathrm{n} . \stackrel{\circ}{ }$ 5692/71 descaracterizou o antigo Curso Normal, introduzindo o mesmo divórcio entre formação geral e específica que já ocorria nas licenciaturas. Deve-se observar ainda que, apesar da ênfase atribuída pela Lei de Diretrizes e Bases à formação em nível superior, não se pode descurar da formação em nível médio, que será, por muito tempo, necessária em muitas regiões do País. Além disso, a formação em nível médio pode cumprir três fun- 
ções essenciais: a primeira é o recrutamento para as licenciaturas, a segunda, a preparação de pessoal auxiliar para creches e pré-escolas, e a última, servir como centro de formação continuada. (MEC 1998)

Ainda que parcial, o reconhecimento do curso atribui significativa importância a essa modalidade de formação e recomenda mudanças em seu atual modelo de organização. Opondo-se aos efeitos da Lei 5692/71 que, tornou obrigatória a profissionalização ao nível do $2^{\circ}$ grau e transformou a formação de professores em "Habilitação para o Magistério", desprovida das condições necessárias ao atendimento de suas reais finalidades, o PNE sugere rever a estrutura fragmentada dos cursos, recomendando como princípio orientador de formação, a articulação teoria e prática.

No âmbito do PNE, elaborado por diversos setores da sociedade brasileira, ao qual foi apensa, no Congresso, a proposta da União, mantém-se a desejabilidade da formação inicial em cursos de licenciatura, sem desconhecer a formação admitida por lei. No caso específico dos professores, a formação mínima exigida por lei é a modalidade Normal do ensino médio, para o trabalho pedagógico na educação infantil e nas séries iniciais do ensino fundamental. A formação desejável, e que será exigida a curto para médio prazo, para todos os níveis e modalidades, far-se-á na educação superior, em cursos de licenciatura plena. (PNE 1997)

Ao tratar da questão em pauta, a Associação Nacional de Pós-Graduação em Educação (ANPED) insiste em que a qualidade da formação docente e a valorização da carreira devem ser consideradas de forma integrada pelas políticas públicas. Ao mesmo tempo estabelece que essa formação superior deve ocorrer nas universidades, pois é aí que se têm no Brasil grande parte da pesquisa e da experiência acumulada sobre o ensino. (ANPED 1997)

Não tem sido diferente o entendimento da Associação Nacional pela Formação dos Professores (ANFOPE) a respeito do tema. Em audiência pública do Conselho Nacional de Educação (13/01/98 - PUC/Rio) sobre a formação dos profissionais da educação, foi divulgado documento da entidade que reafirmava a importância da universidade nesse processo e reconhecia a tendência mundial de elevar a níveis cada vez mais superiores, a formação inicial dos quadros do magistério. (ANFOPE 1997)

Em certo sentido, identificam-se, no bojo de tais análises, abordagens que se diferenciam quanto ao reconhecimento, no momento, do papel histórico do curso Normal. Convergem, por sua vez, quanto ao entendimento de que a formação inicial está situada no trajeto do desenvolvimento profissional permanente tendo, em função disso, que manter vinculações efetivas com o processo de formação continuada. Também revelam-se estrei- 
tamente afinadas com a preocupação de favorecer um processo de transição que deverá ocorrer, no arco da diversidade que se configura no país, sem impedir a expansão da educação infantil e a universalização do ensino fundamental.

Isto não prejudica, obviamente, o reconhecimento que os atuais dispositivos legais conferem ao atendimento educacional através dessa modalidade de educação profissional. Contudo, é preciso lembrar que diversos setores do poder público e da sociedade em geral, ao acolherem essa determinação, identificam nos citados dispositivos uma alternativa essencialmente provisória. Ademais, a nova LDBEN também incorpora a tendência mundial de formação do professor, em nível superior, independente da etapa de sua atuação na educação básica.

Dessa forma, considera, sobretudo, que desde as origens do curso Normal o debate sobre a qualidade da educação nunca se afastou do entendimento que propugna por graus mais elevados de preparação dos profissionais que vão exercer a docência. Por certo, este era o fundamento dos cursos de especialização que ao lado dos dois ciclos do ensino Normal', eram previstos no Decreto-Lei no 8530/46 que instituiu a Lei Orgânica dessa modalidade de ensino. Verifique-se que o acesso a tais cursos, definido no art. 22, estava vinculado ao exercício prévio da docência, situando-se na perspectiva da formação continuada ${ }^{2}$.

Em função disso, o que vai sendo observado ao longo da legislação subseqüente é, cada vez mais, a perspectiva de preparação do professor em níveis mais elevados. Em nome de uma formação mais sólida para o magistério, os cursos normais de 4 e 5 anos, primeiro ciclo, para regentes do ensino primário, bem como os estudos adicionais, foram extintos. Posteriormente, a supressão das licenciaturas curtas traduziram, no ordenamento jurídico, uma compreensão condizente com as novas competências requeridas do professor, numa sociedade perpassada por vertiginosas mudanças e crescente complexidade.

Mais recentemente, o curso Normal, em nível médio, foi inserido numa trajetória cujo horizonte é traduzido, na sua forma mais atual, através dos arts. 62,63 , I e 87, IV da LDBEN. Estes, preconizam sua abertura para o curso Normal superior e para as licenciaturas, sem conferir, no entanto, amparo legal às iniciativas de curso Normal que possam vir a ser definidas fora do que está determinado nos níveis aqui especificados. Isto ocorre na lei sem descaracterizar sua identidade. É um curso próprio para a formação de professores da educação infantil e dos anos iniciais do ensino fundamental, que tem estrutura e estatuto jurídico específicos. Não é um ensino técnico adap- 
tado. Sua identidade, em face do que estabelecem os dispositivos legais, é claramente definida pela contextualização da sua proposta pedagógica, no âmbito das escolas campo de estudo e das experiências educativas às quais os futuros professores têm acesso, seja diretamente, seja através dos recursos tecnológicos disponíveis. Em função dessa concepção, a formação de professores oferecida nessa modalidade requer um ambiente institucional próprio, com organização adequada à sua proposta pedagógica. No caso, os professores formadores deverão, ao longo do curso, orientar sua conduta a partir dos princípios a serem seguidos pelos futuros professores. Exige, também, o nível de estudo do ensino médio, voltado para a educação, nos termos propostos pela LDBEN, nos arts. 21 e 22, enquanto direito de todos e dimensão inalienável da cidadania, na sociedade contemporânea.

Aliás, a importância da educação básica foi enfatizada de forma clara, na Emenda Constitucional 14/96, cujo texto declara o compromisso nacional com a progressiva universalização do ensino médio gratuito, etapa conclusiva do primeiro nível da educação no país. Assim, suas finalidades estão postas na perspectiva da educação enquanto direito, numa sociedade que estabelece, do ponto de vista formal, a possibilidade de universalização da Educação Básica de qualidade, instaurando, sem dúvida, o campo histórico da luta para sua tradução ao nível das condições concretas.

Sob essa ótica, o Parecer 04-98 da Câmara da Educação Básica do CNE (CEB-CNE) contextualizou as diretrizes curriculares para o ensino fundamental no âmbito da educação básica e, ao fazê-lo, associou a conquista da cidadania plena, fruto dos direitos e deveres reconhecidos na Carta Magna, à garantia desse patamar educacional.

Posteriormente, através das diretrizes curriculares para o ensino médio, Parecer 15/98, a Câmara reafirmou essa perspectiva, atribuindo a esta etapa da educação básica, a prerrogativa de direito de todo o cidadão. Ainda, com base na legislação vigente, definiu que a sua natureza de formação básica e comum para todo os cidadãos, mesmo incluindo a preparação básica para o trabalho, não pode ser ajustada ou aligeirada face a outros objetivos, mas deve estabelecer permanentemente a relação teoria e prática.

Sem dicotomizar, o citado parecer estabeleceu a diferença entre os estudos de formação básica e os de natureza estritamente profissionalizante. Aos primeiros, reservou, para assegurar o que está disposto nos arts. 35 e 36 da Lei 9394/96, 2.400 horas de trabalho pedagógico, distribuídos no período de três anos letivos com, no mínimo, 200 dias para cada um. Também estabeleceu que não há impedimentos, salvo a exigência de um limite máximo de $25 \%$ da carga horária mínima deste nível de ensino 
(estabelecidas no Decreto 2208/97), para aproveitamento de tais estudos em cursos profissionais. O inverso não tem suporte legal.

Assim, é apropriado dizer que a formação geral inerente ao ensino médio circunscreve-se no horizonte da cidadania de cada um e de todos. E, neste sentido, é componente do curso Normal médio que subassume essa etapa da educação básica com função habilitadora.

Com isto, o curso Normal, forma docentes para atuar na educação infantil e nos anos iniciais do ensino fundamental, tendo como perspectiva 0 atendimento a crianças, jovens e adultos, acrescendo-se às especificidades de cada um desses grupos, as exigências que são próprias das comunidades indígenas e dos portadores de necessidades especiais de aprendizagem. Assim, além de assegurar titulação específica que habilita, o curso tem também a validade do ensino médio brasileiro, para eventual prosseguimento de estudos.

$\mathrm{Na}$ verdade, a legislação instaura um campo de tensão entre o instituinte e o instituído. Ao acenar com a formação inicial, no horizonte da "universitarização", a perspectiva confronta-se com as dificuldades de uma realidade que não dá conta, por inteiro, das condições necessárias à implementação da inovação proposta. Depende, portanto, de negociações e decisões que deverão contemplar as especificidade locais e os procedimentos que fundamentam a convivência democrática.

Certamente, cabe ao poder público, como gestor das políticas educacionais, "universalizar" o atendimento imediato do ensino obrigatório de qualidade e responder, simultaneamente, às exigências que favoreçam a transição do estágio atual para um novo padrão de formação inicial e continuada do professor. Atingir este patamar pressupõe, por sua vez, a possibilidade de ampliar o acesso às Instituições de Educação Superior, bem como o desenvolvimento de pesquisas que tenham seu foco nas necessidades das escolas e seus respectivos contextos.

Entende-se, com o atendimento dessas exigências, que é possível ampliar o potencial de articulação a ser alcançado entre a melhoria da Educação Básica e as Instituições de Ensino Superior, reduzindo-se os riscos das mesmas transformarem-se em locus de investigação e produção de conhecimentos voltados para a especialização exclusiva de seus próprios docentes. Louvem-se, então, as iniciativas em curso que se anteciparam no engajamento das citadas IES com as demandas dos sistemas de ensino.

Trata-se, como se vê, de um patamar a ser alcançado e de condições a serem criadas, num país que ainda conta com um grande contingente de 
professores leigos, com escolarização no nível do Ensino Fundamental ou do Ensino Médio, sem a habilitação de Magistério. Exercem a docência nas redes estaduais e municipais ( tabela 1), exigindo, particularmente em algumas regiões, uma política de formação continuada que assegure a curto e médio prazo, condições mínimas para o exercício profissional.

\section{Tabela 1 - Funções docentes, por grau de formação dos respectivos ocupantes, nas quatro séries iniciais do Ensino Fundamental - regiões norte, nordeste e centro-oeste-1996}

\begin{tabular}{|c|c|c|c|c|c|c|c|c|}
\hline Nível de & \multicolumn{2}{|c|}{ Fundamental } & \multicolumn{2}{|c|}{ Médio } & \multicolumn{3}{|c|}{ Superior } & \multirow{3}{*}{ Total } \\
\hline & \multirow[t]{2}{*}{ Incompl. } & \multirow[t]{2}{*}{ Completo } & \multirow[t]{2}{*}{ C/Magist. } & \multirow[t]{2}{*}{ S/Magist. } & \multirow{2}{*}{$\begin{array}{l}\mathrm{C} / \\
\text { Licenc. }\end{array}$} & \multicolumn{2}{|c|}{ S/Licenc. } & \\
\hline Região & & & & & & C/Magist. & S/Magist. & \\
\hline Norte & 13.911 & 15.211 & 46.369 & 2.967 & 1.684 & 233 & 75 & 80.450 \\
\hline Nordeste & 60.765 & 38.417 & 189.255 & 9.672 & 20.365 & 2.429 & 503 & 321.406 \\
\hline Centro-Oeste & 2.584 & 3.938 & 31.626 & 2.317 & 12.389 & 1.182 & 203 & 54.239 \\
\hline Total & 77.260 & 57.566 & 267.250 & 14.956 & 34.438 & 3.844 & 781 & 456.095 \\
\hline
\end{tabular}

Fonte MEC/INEP/SEEC

Face a essa realidade, mecanismos disciplinadores da aplicação de recursos na manutenção e no desenvolvimento do ensino obrigatório admitem a possibilidade de financiamento para a formação de professores leigos em exercício. É o caso da Lei 9424/96 que dispõe sobre o Fundo de Manutenção e Desenvolvimento do Ensino Fundamental e da Valorização do Magistério, que em seu art. $7^{\circ}$, parágrafo único, estabelece: Nos primeiros cinco anos, a contar da publicação desta lei, será permitida a aplicação de parte dos recursos da parcela de $60 \%$, prevista neste artigo, na capacitação de professores leigos.

$\mathrm{Na}$ verdade, tanto do ponto de vista legal, quanto da diversidade que perpassa a realidade educacional do país, considera-se que o ensino médio na modalidade Normal, incorporadas as contribuições advindas da legislação educacional e dos estudos recentes a respeito dessa habilitação, representa, no trajeto da profissionalização do educador, uma das alternativas a serem consideradas na definição de políticas integradas para o setor.

Desse modo, a oferta do curso Normal atende o que prescreve a lei e, além de tudo, possibilita ao poder público proceder à passagem da 
formação inicial de nível médio para a de nível superior, sem prejuízo da expansão da educação infantil e da universalização do ensino fundamental. Para tanto, deverá, no mínimo, cumprir os requisitos de qualidade exigidos para profissionais que têm a atribuição de definir, no exercício da atividade pedagógica, o quê e como ensinar.

Sobre o caráter autônomo dessa atividade, vale também observar, seu compromisso com o princípio da liberdade e com o estatuto da convivência democrática nos sistemas de ensino, ambos inspirados na LDBEN. Contudo, seu significado maior está dado, na mesma lei, pelos ideais de solidariedade e pela capacidade de vincular o mundo da escola ao do trabalho e da prática social. Para tanto, no curso Normal em nível médio, os princípios que fundamentam o projeto pedagógico e as práticas escolares que concretizam os ambientes de aprendizagens deverão também ser coerentes com os princípios que iluminam as Diretrizes Curriculares Nacionais para o Ensino Médio (DCNEM), as Diretrizes Curriculares Nacionais para o Ensino Fundamental (DCNEF) e as Diretrizes Curriculares Nacionais para a Educação Infantil (DCNEI).

\section{Bases para as Diretrizes Ourriculares Nacionais}

... Mire veja: o mais importante e bonito, do mundo, é isto: que as pessoas não estão sempre iguais, ainda não foram terminadas - mas que elas vão sempre mudando. Afinam ou desafinam. Verdade maior. É o que a vida me ensinou.

João Guimarães Rosa - Grande Sertão: Veredas

O curso Normal, em função de sua natureza profissional, requer um ambiente institucional próprio com organização adequada à identidade de sua proposta pedagógica. À luz da legislação educacional, deverá prover a formação de professores, em nível médio, para atuar como docentes na educação infantil e nos anos iniciais do ensino fundamental. Na LDBEN as incumbências dos professores estão claramente definidas no art. 13. e, nesse dispositivo, a atividade docente é essencialmente coletiva e contextualizada numa gestão pedagógica cuja pretensão maior é provocar, apoiar e avaliar o processo de aprendizagem dos alunos.

Tendo como horizonte essa perspectiva, o curso deve formar professores autônomos e solidários, capazes de investigar os problemas que se colocam no cotidiano escolar, utilizar os conhecimentos, recursos e procedimentos necessários às suas soluções, avaliar a adequação das escolhas 
que foram efetivadas, e, ainda, devido às transformações por que passam as sociedades, deverão analisar as conseqüências dos novos paradigmas do conhecer. Implicam conhecimentos gerados a partir de um modo de refletir sobre a prática que mantém no direito do aluno aprender, no esforço nacional de construção de um projeto de educação escolar de qualidade para o país, e nas regras da convivência democrática, as referências que norteiam permanentemente a ação pedagógica.

Assim, as diretrizes curriculares para o curso Normal em nível médio deverão ser inspiradas nos princípios éticos, políticos e estéticos já declarados nos Pareceres de $n^{\text {os }} 22 / 98,04 / 98$ e 15/98, a respeito da educação infantil e do ensino fundamental e médio. Na organização das propostas pedagógicas, as escolas deverão assumi-los como ponto de partida e foco de iluminação para todo o percurso da formação dos professores:

I - Na efetivação desses princípios, as práticas educativas desenvolvidas no curso Normal são constitutivas de sentimentos e consciências. Constroem, utilizando abordagens condizentes com o exercício da cidadania plena na sociedade contemporânea, as identidades dos alunos (futuros professores), que deverão vivenciar situações de estudos e aprendizagens nas quais são consideradas as especificidades do processo de pensamento, a realidade sócio-econômica, a diversidade cultural, étnica, de religião e de gênero.

II - No exercício da autonomia, as escolas normais de nível médio deverão elaborar propostas pedagógicas mobilizadoras de mentes e afetos, propiciando, na perspectiva da cidadania plena, a conexão entre conhecimentos, valores norteadores da educação escolar e experiências que provêm das realidades específicas de alunos e professores. Suas histórias de vida são importantes. Aqueles que ensinam e aprendem têm uma história que se expressa em todas as suas atitudes, na postura profissional e no modo de ensinar, pensar e aprender. Ao considerar princípios éticos, políticos e estéticos na reinterpretação de histórias que se influenciam e modificam umas as outras, a escola reconhece as identidades pessoais e assegura a reelaboração crítica do conhecimento de si e do seu relacionamento com os demais durante o processo de formação. Ensinar/aprender é, portanto, um movimento sensível ao inesperado e aberto, numa sociedade instituinte, à singularidade dos pensamentos e sentimentos. Pressupõe, nesse sentido, a competência dos professores para tomar decisões que nem sempre constam do elenco de saberes e experiências já vistos e conhecidos, por inteiro.

III - A clareza a respeito das competências e capacidades cognitivas sociais e afetivas pretendidas como objetivos do curso normal de nível mé- 
dio, é decisiva para o diálogo entre os integrantes da comunidade escolar, o conjunto da sociedade e entre as áreas curriculares na relação com os múltiplos aspectos da vida cidadã, com vista ao desenvolvimento da proposta pedagógica. Na verdade, o diálogo é proposto como a base do ato pedagógico, caracterizando o princípio da autonomia da escola através de um modelo de gestão que é, de um lado, um convite para "sair do isolamento e romper fronteiras" e, de outro, um esforço especulativo e questionador da versão social do que vem sendo considerado e aceito como aprendizagens significativas, num determinado contexto. De fato, o diálogo reveste de especial importância, dada a repercussão que tem na formação de futuros professores, a experiência vivida na condição de alunos do curso Normal.

IV - Na estruturação das propostas pedagógicas, a ênfase dada ao diálogo em todas as suas formas deverá preparar os professores para lidar com um paradigma curricular que articule conhecimentos e valores, em áreas ou núcleos curriculares que interagem no processo de constituição de conhecimento, valores e competências necessárias ao exercício da docência na educação infantil e nos anos iniciais do ensino fundamental. Dessa forma, as áreas ou núcleos curriculares possibilitarão a formação básica geral e comum, a compreensão da gestão pedagógica no âmbito da educação escolar contextualizada e a produção de conhecimento a partir da reflexão permanente sobre a prática. O diálogo também deve ser instalado entre as áreas de conhecimento e o modo particular de inserção dos alunos (do curso normal) na vida social, considerando, nos termos das DCN para a educação infantil e o ensino fundamental, os diversos aspectos da vida cidadã.

V - A formação básica, geral e comum, considerada direito inalienável e condição necessária ao exercício da cidadania plena, deverá assegurar, no curso Normal, os conhecimentos e competências previstos para a terceira etapa da educação básica, nos termos do que estabelece a Lei 9394/96, nos arts. 35 e 36, explicitados, posteriormente, no Parecer no 15/98 da CEBCNE. Enquanto dimensão do processo integrado de formação de professores em nível médio, sua abordagem é remetida aos ambientes de aprendizagem planejados e desenvolvidos na escola campo de estudo e investigação. Nesse sentido, além de contemplar conteúdos e competências de caráter geral, incluirá as áreas que integram o currículo destinado à educação infantil e aos anos iniciais do ensino fundamental em níveis de abrangência e complexidade indispensáveis à (re)significação de conhecimentos e valores nas situações pedagógicas em que são (des)construídos/(re)construídos por crianças, jovens e adultos. Assim sendo, é necessário em articulação com as demais áreas que constituem o curso, expor os estudantes a situações do cotidiano escolar que sejam estimuladoras das competências e capacidades 
cognitivas sociais e afetivas que serão exigidas, posteriormente, no exercício da docência.

Por isso, o professor formador, independente de sua área de atuação levará em consideração as influências do processo de comunicação na formação dos docentes, pautando suas ações pelos mesmos princípios que orientam a inserção dos alunos no conjunto das atividades do projeto pedagógico das escolas campo de estudo.

$\mathrm{VI}$ - A reflexão sistemática sobre o saber do fazer de cada professor e da escola como um todo é impulsionadora do processo de produção do conhecimento que se instaura como uma atividade crítica desde as origens da formação do professor. No curso Normal, a reflexão sistemática sobre a prática deve conferir validade aos estudos e às experiências a que são expostos alunos e professores. Ao eleger o fazer como o objeto da reflexão, a formação é concebida a partir do envolvimento dos alunos e professores em situações complexas, cuja intervenção exige a explicitação de conhecimentos e valores que referenciam competências afinadas com uma concepção de professor reflexivo, dotado da capacidade intelectual, autonomia e postura ética, indispensáveis ao questionamento das interpretações que apoiam, inclusive, suas intervenções no exercício da atividade profissional. O professor, nesse caso, é sujeito do seu conhecimento e se define como intelectual no âmbito de sua atividade profissional que é reconhecidamente 'prática e contextualizada'.

VII - As escolas, com seus desafios e soluções, ao se tornarem campo de estudo e investigação dos alunos do curso Normal, devem enriquecer a sistematização da reflexão sobre a prática, submetendo-se a um processo de avaliação permanente que identifique a adequação entre as pretensões do curso e a qualidade das decisões que são tomadas pela instituição. A educação escolar, espaço de igualdade e de direitos, é uma prática social que se viabiliza sob a responsabilidade da Família e do Estado. Enquanto atividade pública, que pretende assegurar as condições necessárias ao exercício de um direito socialmente conquistado e legalmente constituído, deverá, através da proposta pedagógica da escola, incorporar representantes de todos os segmentos da escola, alunos da escola campo de estudo, futuros professores, bem como as respectivas famílias, grupos sociais e comunidade, num processo de avaliação que envolva todas as dimensões dessa proposta.

A perspectiva é construir a qualidade da educação escolar, ancorando-se, para tanto, nos princípios da gestão democrática, nos termos da CF e da LDBEN, garantindo o controle público das políticas dispostas. 
VIII - A gestão pedagógica, no âmbito da educação escolar contextualizada, deverá, em diálogo com as demais áreas ou núcleos curriculares da proposta pedagógica, desenvolver práticas educativas que integram os múltiplos aspectos constitutivos da identidade dos alunos (futuros professores), que se deseja sejam afirmativas, responsáveis e capazes de protagonizar ações autônomas e solidárias no universo das suas relações. Nessa abordagem, a problematização das escolhas e dos resultados que demarcam a identidade da proposta pedagógica das escolas nas quais a gestão pedagógica da educação escolar observada é vivenciada, tomam como objeto de análise a escola como instituição social determinada e determinante, a legislação educacional e os diversos sistemas de ensino no horizonte dos direitos dos cidadãos e do respeito ao bem e à ordem democrática, os alunos em suas diversas etapas de desenvolvimento e suas relações com o universo familiar, comunitário e social, o impacto dessas relações sobre as capacidades, habilidades e atitudes dos alunos em relação a si próprios, seus companheiros e aos objetos e materiais de estudo. Na formação dos futuros docentes isto pode ser aprendido através de conteúdos da sociologia educacional, psicologia educacional, antropologia cultural, história, comunicação, informática, artes e cultura, entre outras. Valendo-se dos conhecimentos específicos dessas e de outras áreas, os professores poderão, ao tratá-los de forma integrada, fazer escolhas a partir do estudo crítico de diferentes orientações teórico-metodológicas. Portanto, as práticas educativas levam em consideração, não só a realidade cultural, social, econômica, de gênero e de etnia, mas também a centralidade da educação escolar no conjunto das prioridades consensuadas no país.

IX - A prática, circunscrita ao processo de investigação e participação dos alunos no conjunto das atividades que se desenvolvem na escola campo de estudo, é instituída no início da formação, prolongando-se ao longo do curso e com duração mínima de 800 horas. Em função da sua natureza, a prática antecipa situações que são próprias da atividade dos professores no exercício da docência, gerando conhecimento, valores e uma progressiva segurança dos alunos do curso normal, no domínio da sua futura profissão. Na verdade, deve estabelecer o contato dos alunos com o mundo do trabalho e a prática social, conforme determina 0 art. $1^{\circ}$ da LDBEN. A tematização da prática oferece informações para a compreensão dos problemas que emergem do cotidiano escolar, gerando conhecimentos para a formulação de soluções originais e adequadas. Nesse processo, a proposta pedagógica da escola, utilizando os instrumentos tecnológicos disponíveis deve oportunizar 
o acesso dos alunos, ao espaço mundial e integrado de conhecimentos a respeito da qualidade social da educação escolar.

$X$ - O curso, considerada a flexibilidade da LDBEN, tem, a critério da proposta pedagógica da escola, amplas e diversas possibilidades de organização. Sua duração, no entanto, será de no mínimo 3.200 horas, distribuídas em 4 (quatro) anos letivos. A possibilidade de cumprir a carga horária mínima em 3 (três) anos, fica condicionada ao desenvolvimento do curso em período integral, contemplando o que está previsto nos termos da formação geral, básica e comum, estabelecida para o ensino médio que será, por sua vez, desenvolvida no contexto das incumbências do professor da educação infantil e dos anos iniciais do ensino fundamental.

Assim, a formação inicial pressupõe conhecimentos e competências referenciados às condições de profissionalização de educadores capazes de estimular procedimentos e desenvolver práticas educativas que sejam constituidoras de indivíduos autônomos e protagonistas da construção mais significativa do processo educativo: o exercício da sua liberdade no contexto das relações éticas que propugnam por uma trajetória da humanidade no horizonte da democracia.

\section{II - Voto da relatora}

À luz do exposto e analisado, em obediência ao artigo $9^{\circ}$ da Lei 9131/95 que incumbe à Câmara de Educação Básica a deliberação sobre Diretrizes Curriculares Nacionais, a relatora vota no sentido de que seja aprovado o texto ora proposto como base do Projeto de Resolução que fixa as Diretrizes Curriculares Nacionais para o Curso Normal em nível médio.

Brasília(DF), 29 de Janeiro de 1999. Conselheira Edla de Araújo Lira Soares

Relatora

\section{III -Decisão da Câmara}

A Câmara de Educação Básica acompanha, unanimemente, o voto da Relatora e aprova o Projeto de Resolução que se segue.

Brasília, 29 de janeiro de 1999.

Ulysses de Oliveira Panisset Presidente da CEB/CNE 


\section{Notas}

1. Um dos ciclos estava voltado para a formação de regentes de ensino primário, em quatro anos, e o outro, o curso de formação de professores primários, era desenvolvido em três anos, após o ginasial.

2. Art. 22 - Os candidatos à matrícula em cursos de especialização de magistério primário deverão apresentar diploma de conclusão do curso de segundo ciclo e prova de exercício do magistério primário por dois anos, no mínimo; os candidatos à matrícula em cursos de administradores escolares, ou funções auxiliares de administração, deverão apresentar igual diploma, e prova do exercício do magistério por três anos no mínimo.

\section{BIBLIOGRA月A}

ANFOPE. VIII Encontro Nacional. Documento gerador. Formação de profissionais da educação. Desafios para o século XXI. Goiânia, 1996. Mimeo.

ANPED. Parecer sobre a proposta elaborada pelo MEC para o Plano Nacional de Educação. São Paulo, Anped, 1997.

BRASIL Constituição da República Federativa. 1988. . Emenda Constitucional no 14 de 12 de setembro de 1996.

- Lei de Diretrizes e Bases da Educação Nacional - nº 9394/96. . Lei no 9424, de 24 de dezembro de 1996.

- Leis Orgânicas do Ensino. O Ensino Normal. 1946.

. MEC/SEF/COEDI - Por uma Política de Formação do Profissional de Educação Infantil. Brasil, 1994.

. MEC/SEF - Referenciais curriculares para a formação de professores. 1998

. Plano Nacional de Educação. 1998.

. CB/CNE. Diretrizes Curriculares para a Educação Básica. 1998.

COLL, César. Psicologia y Currículum. Barcelona: Paidós, 1991.

- Desenvolvimento Psicológico e Educação - Psicologia da Educação, Porto Alegre: Artes Médicas, 1996. 
CNTE. Educação, carinho e trabalho. Petrópolis: Editora vozes, 1997.

CURY, Carlos Roberto Jamil e HORTA, Vera Lúcia. Medo à liberdade e compromisso democrático: LDB e Plano Nacional de Educação. São Paulo, Ed. Brasil, 1997.

DOWBOR, lanni e REZENDE (orgs.) Desafios da globalização. Petrópolis, RJ: Vozes, 1997.

FERNANDES, Florestan. A formação política e o trabalho do professor. In Universidade, Escola e Formação de Professores. São Paulo: Ed. Brasiliense, 1986.

FORQUIN, Jean-Claude. Educação e Cultura. 1993.

GADOTTI, M.: Paulo Freire: uma bibliografia. 1996.

GATTI, Bernadete Angelina. "Formação de professores e carreira: problemas e movimentos de renovação" - Coleção formação de professores. Campinas, São Paulo: Autores Associados, 1997.

GIROUX, Henry. Os professores como intelectuais: rumo a uma pedagogia crítica da aprendizagem. Porto Alegre: Artes Médicas, 1997.

GONÇALVES, Carlos Luiz e PIMENTA, Selma Garrido. Revendo o ensino de $2^{\circ}$ grau: propondo a formação de professores. São Paulo: Ed. Cortez, 1997.

KINCHELVE, Joe L. A formação do professor como compromisso político. Porto Alegre: Artes Médicas, 1997.

LEFOR. C. A invenção democrática - os limites do autoritarismo. São Paulo: Brasiliense, 1987

NÓVOA, Antônio. Para um estudo sócio-histórico e desenvolvimento da profissão docente. In: Teoria e Educação. Porto Alegre: Ed. Panorâmica, 1991.

PERRENOUD, Phillippe. Formar os professores do primeiro grau à Universidade: aposta de Genebra. Universidade de Genebra, 1996. Mimeo.

. Ensinar saberes ou desenvolver competências. Universidade de Genebra. Mimeo.

PIMENTA, Garrido Selma. Didática e Formação de Professores: percursos e perspectivas no Brasil e em Portugal. São Paulo: Ed. Cortez, 1997.

PLANO NACIONAL DE EDUCAÇÃO - Proposta da Sociedade Brasileira. 1997

ROMANELLI, Oliveira O. História da Educação no Brasil. Petrópolis: Vozes, 1978.

TORRES, Rosa Maria. Formación Docente: Clave de la reforma educativa. Texto apresentado no Seminário "Nuevas formas de aprender y de 
enseñar: Demandas a la formación inicial del docente". CIDE/ UNESCO-OREALC/UNICEF, Chile, Santiago, 1985. Mimeo.

- Profesionalización o Exclusion: Los educadores frente a la realidad actual y los desafios futuros. Texto apresentado na Conferência Internacional de Educação, organizada pela Confederação de Educadores da América (CEA), México, 1997. Mimeo.

\title{
Ministério da educação e do desporto Conselho Nacional de Educação
}

\begin{abstract}
Resolução $\mathrm{n}^{\circ}$ _CEB/CNE, de 29 de janeiro de 1999
Institui Diretrizes Curriculares Nacionais para a Formação de Docentes da Educação Infantil e dos anos iniciais do Ensino Fundamental, em nível médio, na modalidade Normal.
\end{abstract}

O Presidente da Câmara de Educação Básica do Conselho Nacional de Educação, de conformidade com o disposto no art. $9^{\circ}, \S 1^{\circ}$, alínea "c", da Lei no 9131, de 24 de novembro de 1995, nos artigos 13, $26,29,35,36,37,38,58,59,61,62$ e 65 da Lei 9394 de 20 de dezembro de 1996, e tendo em vista o Parecer CEB/CNE, de 001/99 de janeiro de 1999, homologado nos termos do art. $2^{\circ}$ da Lei $n^{\circ}$ 9131/95,

\section{RESOLVE,}

Art. $1^{\circ}$ - O Curso Normal em nível Médio, previsto no artigo 62 da Lei no 9394/96, aberto aos concluintes do Ensino Fundamental, deve prover, em atendimento ao disposto na Carta Magna e na Lei de Diretrizes e Bases da Educação Nacional, LDBEN, a formação de professores para atuar como docentes na Educação Infantil e nos anos iniciais do Ensino Fundamental, acrescendo-se às especificidades de cada um desses grupos as exigências que são próprias das comunidades indígenas e dos portadores de necessidades educativas especiais.

$\S 1^{\circ}$ - O curso, em função da sua natureza profissional, requer ambiente institucional próprio com organização adequada à identidade da sua proposta pedagógica.

$\S 2^{0}$ - A proposta pedagógica de cada escola deve assegurar a constituição de valores, conhecimentos e competências gerais e específicas necessárias ao exercício da atividade docente que, sob a ótica do direito, 
possibilite o compromisso dos sistemas de ensino com a educação escolar de qualidade para as crianças, os jovens e adultos.

Art. $2^{\circ}$ - Nos diversos sistemas de ensino, as propostas pedagógicas das escolas de formação de docentes, inspiradas nos princípios éticos, políticos e estéticos, já declarados em Pareceres e Resoluções CEB/CNE, a respeito das Diretrizes Curriculares Nacionais para a Educação Infantil, o Ensino Fundamental e Médio, deverão preparar professores capazes de :

I- integrar-se ao esforço coletivo de elaboração, desenvolvimento e avaliação da proposta pedagógica da escola, tendo como perspectiva um projeto global de construção de um novo patamar de qualidade para a educação básica no país;

II- investigar problemas que se colocam no cotidiano escolar e construir soluções criativas mediante reflexão socialmente contextualizada e teoricamente fundamentada sobre a prática;

III- desenvolver práticas educativas que contemplem o modo singular de inserção dos alunos, futuros professores, e dos estudantes da escola campo de estudo no mundo social, considerando abordagens condizentes com as suas identidades e o exercício da cidadania plena, ou seja, as especificidades do processo de pensamento, da realidade sócio-econômica, da diversidade cultural, étnica, de religião e de gênero, nas situações de aprendizagem;

IV- avaliar a adequação das escolhas feitas no exercício da docência, à luz do processo constitutivo da identidade cidadã de todos os integrantes da comunidade escolar, das diretrizes curriculares nacionais da educação básica e das regras da convivência democrática;

V- utilizar linguagens tecnológicas em educação, disponibilizando, na sociedade de comunicação e informação, o acesso democrático a diversos valores e conhecimentos.

Art. $3^{\circ}$ - $\mathrm{Na}$ organização das propostas pedagógicas para o curso Normal, os valores, procedimentos e conhecimentos que referenciam as habilidades e competências gerais e específicas previstas na formação dos professores em nível médio serão estruturados em áreas ou núcleos curriculares.

$\S 1^{\circ}$ - As áreas ou os núcleos curriculares são constitutivos de conhecimentos, valores e competências e deverão assegurar a formação básica, geral e comum, a compreensão da gestão pedagógica no âmbito da educação escolar contextualizada e a produção de conhecimentos a partir da reflexão sistemática sobre a prática. 
$\S 2^{\circ}$ - A articulação das áreas ou dos núcleos curriculares será assegurada através do diálogo instaurado entre as múltiplas dimensões do processo de aprendizagem, os conhecimentos, os valores e os vários aspectos da vida cidadã.

$\S$ 3ํ- - Na observância do que estabelece o presente artigo, a proposta pedagógica para formação dos futuros professores deverá garantir o domínio dos conteúdos curriculares necessários à constituição de competência gerais e específicas, tendo como referências básicas:

I - o disposto nos artigos 26, 27, 35 e 36 da LDBEN;

II - o estabelecido nas diretrizes curriculares nacionais para a educação básica;

III - os conhecimentos de filosofia, sociologia, história e psicologia educacional, da antropologia, da comunicação, da informática, das artes, da cultura e da lingüística, entre outras.

$\S 4^{\circ}$ - A duração do curso normal em nível médio, considerado o conjunto dos núcleos ou áreas curriculares, será de no mínimo 3200 horas, distribuídas em 4 (quatro) anos letivos, admitindo-se:

I - a possibilidade de cumprir a carga horária mínima em 3(três) anos, condicionada ao desenvolvimento do curso com jornada diária em tempo integral;

II - o aproveitamento de estudos realizados em nível médio para cumprimento da carga horária mínima, após a matrícula, obedecidas as exigências da proposta pedagógica e observados os princípios contemplados nestas diretrizes, em especial a articulação teoria e prática ao longo do curso.

Art. $4^{\circ}$ - No desenvolvimento das propostas pedagógicas das escolas, os professores formadores, independente da área ou núcleo onde atuam, pautarão a abordagem dos conteúdos e as relações com os alunos em formação, nos mesmos princípios que são propostos como orientadores da participação dos futuros docentes nas atividades da escola campo de estudo, bem como no exercício permanente da docência.

Art. $5^{\circ}$ - A formação básica, geral e comum, direito inalienável e condição necessária ao exercício da cidadania plena, deverá assegurar no curso Normal, as competências gerais e os conhecimentos que são previstos para a terceira etapa da educação básica, nos termos do que estabelecem a Lei no 9394/96 - LDBEN, nos arts. 35 e 36, e o Parecer 15/98, da CEB/CNE.

$\S 1^{\circ}$ - Enquanto dimensão do processo integrado de formação de professores, os conteúdos curriculares dessa área serão remetidos a ambientes de aprendizagem planejados e desenvolvidos na escola campo de estudo. 
$\S 2^{\circ}$ - Os conteúdos curriculares destinados à educação infantil e aos anos iniciais do ensino fundamental serão tratados em níveis de abrangência e complexidade necessários à (re)significação de conhecimentos e valores, nas situações em que são (des)construídos/(re)construídos por crianças, jovens e adultos.

Art.6- A área ou o núcleo da gestão pedagógica no âmbito da educação escolar contextualizada, em diálogo com as demais áreas ou núcleos curriculares das propostas pedagógicas das escolas, propiciará o desenvolvimento de práticas educativas que:

I - integrem os múltiplos aspectos constitutivos da identidade dos alunos, que se deseja sejam afirmativas, responsáveis e capazes de protagonizar ações autônomas e solidárias no universo das suas relações;

II - considerem a realidade cultural, sócio-econômica, de gênero e de etnia, e também a centralidade da educação escolar no conjunto das prioridades sociais a serem consensuadas no país.

Parágrafo Único - Nessa abordagem, a problematização das escolhas e dos resultados que demarcam a identidade da proposta pedagógica das escolas campo de estudo toma como objeto de análise:

I - a escola como instituição social, sua dinâmica interna e suas relações com o conjunto da sociedade, a organização educacional, a gestão da escola e os diversos sistemas de ensino, no horizonte dos direitos dos cidadãos e do respeito ao bem comum e à ordem democrática;

II - os alunos nas diferentes fases de seu desenvolvimento e em suas relações com o universo familiar, comunitário e social, bem como o impacto dessas relações sobre as capacidades, habilidades e atitudes dos estudantes em relação a si próprios, aos seus companheiros e ao conjunto das iniciativas que concretizam as propostas pedagógicas das escolas.

Art. $7^{\circ}$ - A prática, área curricular circunscrita ao processo de investigação e à participação dos alunos no conjunto das atividades que se desenvolvem na escola campo de estudo, deve cumprir o que determinam especialmente os artigos $1^{\circ}$ e 61 da LDBEN antecipando, em função da sua natureza, situações que são próprias da atividade dos professores no exercício da docência, nos termos do disposto no artigo 13 da citada Lei.

$\S 1^{\circ}$ A parte prática da formação, instituída desde o início do curso, com duração mínima de 800 (oitocentas) horas, contextualiza e transversaliza as demais áreas curriculares, associando teoria e prática. 
$\S 2^{\circ}$ O efetivo exercício da docência na educação infantil e nos anos iniciais do ensino fundamental, pelos alunos em formação, é parte integrante e significativa dessa área curricular.

$\S 3$ ํ. Cabe aos respectivos sistemas de ensino, em cumprimento ao disposto no parágrafo anterior, estabelecer a carga horária mínima dessa docência.

Art. $8^{\circ}$ - Os cursos normais serão sistematicamente avaliados, assegurando o controle público da adequação entre as pretensões do curso e a qualidade das decisões que são tomadas pela instituição, durante o processo de formulação e desenvolvimento da proposta pedagógica.

Art. 9 - As escolas de formação de professores em nível médio na modalidade Normal, poderão organizar, no exercício da sua autonomia e considerando as realidades específicas, propostas pedagógicas que preparem os docentes para as seguintes áreas de atuação, conjugadas ou não:

I - educação infantil;

II - educação nos anos iniciais do ensino fundamental;

III - educação nas comunidades indígenas;

IV - educação de jovens e adultos;

V - educação de portadores de necessidades educativas especiais.

Art. $10^{\circ}$ - Cabe aos órgãos normativos dos sistemas de ensino, em face da diversidade regional e local e do pacto federativo, estabelecer as normas complementares à implementação dessas diretrizes.

Art. $11^{\circ}$ - Esta Resolução entra em vigor na data de sua publicação.

Art. $12^{\circ}-$ Revogam-se as disposições em contrário.

Brasília, 29 de janeiro de 1999.

Ulysses de Oliveira Panisset

Presidente da CEB/CNE 